\section{Elusive fossil could conceal answ er to dinosaur debate}

Rex Dalton, San Diego

A Chinese dinosaur fossil of immense potential interest to palaeontologists is circulating between private dealers in Europe, highlighting scientists' concern that the underground trade in such artefacts is inhibiting their study.

The fossil of a psittacosaurid is special because it has outer coverings, known as integuments, protruding along the tail, something not previously observed in the dinosaur group to which it belongs. If it were to be established that these protrusions carried hair or feathers, that could mean that most dinosaurs had these features.

Mark Norell, an expert on Asian dinosaurs at the American Museum of Natural History in New York, says the story is a telling example of how private dealings can hide important scientific discoveries. "This specimen could redefine how we look at dinosaurs," he says. "But we can't say, since no one has studied and published on it. It should be returned to China, where it can be studied in a museum."

According to interviews with palaeontologists and dealers, the fossil has made a mysterious journey through Italy and Germany over the past two years. It was last heard of in the hands of a German dealer.

In recent weeks, the fossil has been the subject of extensive discussion on palaeontology websites, prompted by the publication of a painting thought to show a psittacosaurid in the popular book Extreme Dinosaurs by Luis Rey.

There are two orders of dinosaurs: Saurischia and Ornithischia, the latter of which includes psittacosaurids. Some saurischid fossils show integuments, but none have been positively identified on ornithischids, which would make the psittacosaurid specimen an important first.

Last year, the fossil was being kept in a shop called Stone Age in Trieste, Italy. The shop's proprietor, Flavio Bacchia, says that the German dealer, a geologist, had given him the specimen for cleaning. Bacchia says he sent the fossil for study to palaeontologists at Milan's natural history museum.

A museum researcher says that the fossil was examined there in some detail, but that Bacchia then requested its return. Bacchia says he has now returned the fossil to the German dealer, who did not respond to an interview request. Bacchia also says that while the fossil was in Italy, a failed attempt was made to arrange a collaborative study of it with Chinese palaeontologists.

www.cmnh.org/fun/dinosaur-archive

\title{
Staff survey shows women feel out in the cold at Caltech
}

\section{Rex Dalton, San Diego}

Women staff at the California Institute of Technology are highly dissatisfied with academic conditions there, according to an internal study that has also found they are paid less than men at the prestigious university.

The investigation finds that women are unhappy with the economic support for their positions, their lack of involvement in faculty leadership, and the method by which they are promoted and receive tenure.

"The study shows a lot of dissatisfaction among women," says astronomer Anneila Sargent, chair of the faculty committee that conducted the two-year study. The committee is now preparing recommendations for Caltech administrators about the issues it raises.

Among the 283 academic staff at Caltech during the period studied, only 27 were women. But over one-third of undergraduates and one-quarter of graduate students there are women.

The study found that $54 \%$ of women were dissatisfied or had reservations about their career advancement, compared with $27 \%$ of men. Almost two-thirds of the women were dissatisfied or had reservations about faculty

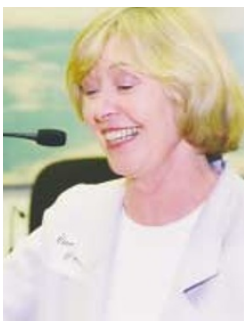

Anneila Sargent says Caltech's women staff are unhappy.

the issues, and will try to address whatever imbalances there are."

Sargent's committee is likely to recommend changes in how women are promoted and given tenure, and in the openness of academic affairs. "When a process is not transparent, there is always room for a perception of injustice," says Sargent.

The study also found that women were paid less than men, although no figures are disclosed in its report. "Clearly, if there are inequities in salaries we will need to take a serious look at that," says Steve Koonin, provost of the institute.

\section{LED pioneer seeks reward in court}

David Cyranoski, Tokyo

A prominent Japanese materials scientist is suing his former employer for $¥ 2$ billion

(US\$16.5 million) over the level of compensation he received for inventing the technology behind blue light-emitting diodes (LEDs).

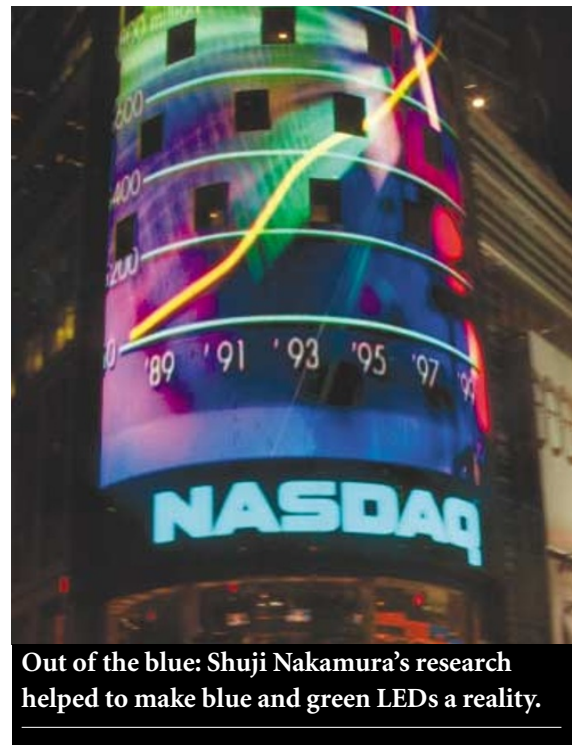

The claim - filed by Shuji Nakamura, now at the University of California, Santa Barbara, against Nichia Corporation of Shikoku - has sent shock waves through Japanese industrial research.

LEDs are semiconductor-based devices that convert electrical current into light. Nakamura is suing Nichia in Tokyo's district court over a patent, filed in 1991, covering a processing method for making the lightproducing layer of gallium nitride-based semiconductors. Nichia, where Nakamura worked from 1979 to 1999 , used this technology to produce blue and green LEDs as well as blue lasers.

Nakamura is basing his case on Japan's ambiguous patent law, under which researchers should get "fair compensation" for their patented research. Researchers do not usually have contracts with detailed reward provisions. "We need this kind of case to force employers to make clear reward conditions for inventors," says Nakamura.

Nakamura is claiming ownership, in part or in full, of the patent, and wants the technology to be licensed to outside manufacturers. "Nichia will not license it to others," he says. 